\title{
Alih Kode dan Campur Kode di Pasar Tradisional Kedondong dan Implikasinya
}

\author{
Oleh \\ M. Suhendra \\ Siti Samhati \\ Eka Sofia Agustina \\ Fakultas Keguruan dan Ilmu Pendidikan Universitas Lampung \\ e-mail : msuhendra296@gmail.com
}

\begin{abstract}
The problems discussed in this study are code switching and code mixing in Kedondong traditional market. This study aims to describe the shape and factors causes of code switching and code mixing in the Kedondong traditional market and its implications for learning Indonesian in high school. The method used in this study is qualitative descriptive. The data source in this study is the conversation of the traders at Kedondong traditional market. Data collection techniques used in this study are field notes and audio recordings. The results of the research that has been done there is a form of internal code switching caused by speakers and opponents. the mixed code form in the Kedondong traditional market consists of words, phrases, and clauses caused by the background of speakers' attitudes, language, code limitations, and speaker.
\end{abstract}

Keywords : code transfer, mix code, Kedondong tradisional market.

\begin{abstract}
ABSTRAK
Masalah yang dibahas dalam penelitian ini adalah alih kode dan campur kode di pasar tradisional Kedondong. Penelitian ini bertujuan untuk mendeskripsikan bentuk dan faktor penyebab alih kode dan campur kode di pasar tradisional Kedondong dan implikasinya pada pembelajaran bahasa Indonesia di SMA . Metode yang digunakan dalam penelitian ini adalah deskriptif kualitatif. Sumber data dalam penelitian ini ialah percakapan para pedagang di pasar tradisional Kedondong. Teknik pengumpulan data yang digunakan dalam penelitian ini adalah catatan lapangan dan rekaman audio. Hasil dari penelitian yang telah dilakukan terdapat bentuk alih kode internal yang disebabkan oleh faktor penutur dan lawan tutur. bentuk campur kode di pasar tradisional Kedondong terdapat bentuk kata, frasa,dan klausa yang disebabkan oleh latar belakang sikap penutur, kebahasaan, keterbatasan kode, dan pembicara.
\end{abstract}

Kata kunci : alih kode, campur kode, pasar tradisional Kedondong 


\section{PENDAHULUAN}

Bahasa adalah alat yang ampuh untuk menghubungkan dunia seseorang dengan dunia di luar diri kita, dunia seseorang dengan lingkungannya, dunia seseorang dengan alamnya bahkan dunia seseorang dengan Tuhannya. Jelaslah bahwa bahasa bersifat instrumentalis, alat penghubung antara diri kita dengan lingkungan kita (Pateda, 2011: 6).

Dalam suatu masyarakat, manusia tidak mungkin dapat berkomunikasi apabila anggota masyarakat tersebut tidak menggunakan bahasa sebagai media atau sasaranya. Manusia bukan makhluk individu, melainkan makhluk sosial yang di dalam keseharianya membutuhkan yang namanya bahasa. Tanpa adanya Bahasa, manusia belum bisa dikatakan makhluk sosial (Nababan, 1984:46).

Banyaknya suku dan bahasa di Indonesia maka, tidak menutup kemungkinan adanya masyarakat bilingual atau multilingual dalam berinteraksi di masyarakat. Penggunaan bilingualisme oleh masyarakat tertentu terjadi karena adanya kontak bahasa, seorang individu satu dengan individu lainya akan saling mempengaruhi terhadap penggunaan bahasa satu dengan bahasa lainya, baik secara langsung ataupun tidak langsung. Hal inilah yang menciptakan terjadinya alih kode dan campur kode karena masyarakat bilingual atau multilingual sering mencampuradukan dua bahasa atau bahkan beralih dari satu bahasa ke bahasa lainya dalam bertutur.

Kridalaksana (2008:9) mengungkapkan bahwa alih kode merupakan penggunaan variasi bahasa lain atau bahasa lain dalam satu peristiwa bahasa sebagai strategi untuk menyesuaikan diri dengan peran atau situasi lain. Soewito (dalam Chaer dan Agustina, 2010: 114) membedakan dua macam alih kode yaitu alih kode internal dan alih kode eksternal. Alih kode internal adalah alih kode yang berlangsung antara bahasa sendiri, seperti dari bahasa Indonesia ke bahasa Jawa atau sebaliknya. Sedangkan alih kode eksternal terjadi antara bahasa sendiri (salah satu bahasa atau ragam yang ada dalam verbal repertoire masyarakat tuturnya) dengan bahasa asing.

Suwito (1983: 72) mengungkapkan faktorfaktor yang dapat memengaruhi terjadinya alih kode antara lain, (1) penutur, (2) lawan tutur, (3) hadirnya penutur ketiga, (4) pokok pembicaraan, (5) untuk membangkitkan rasa humor, dan (6) untuk sekedar bergengsi.

Suyanto (2011: 83) menyatakan bahwa campur kode merupakan peristiwa pencampuran dua atau lebih bahasa atau ragam bahasa dalam suatu peristiwa tutur. Aslinda dan Syafyahya (2014 : 87) campur kode terjadi apabila seseorang penutur bahasa, misalnya bahasa Indonesia memasukan unsur-unsur bahasa daerahnya ke dalam pembicaraan bahasa Indonesia.

(Suandi, 2014: 140) menyatakan bahwa terdapat beberapa ciri campur kode yang membedakannya dengan alih kode, yaitu. 1. Campur kode tidak dituntut oleh situasi dan konteks pembicaraan seperti yang terjadi dalam alih kode, tetapi bergantung kepada pembicaranya (fungsi bahasa).

2. Campur kode terjadi karena kesantaian pembicara dan kebiasaannya dalam bahasa.

3. Campur kode pada umumnya terjadi dan lebih banyak dalam situasi tidak resmi.

4. Campur kode berciri pada ruang lingkup di bawah klausa pada tataran yang paling tinggi dan kata pada tataran yang terendah.

Peneliti merasa penting meneliti alih kode dan campur kode dalam percakapan di pasar tradisional Kedondong karena, di 
pasar adalah tempat berkumpulnya seluruh lapisan masyarakat.

Pasar merupakan tempat berkumpulnya penjual dan pembeli untuk melakukan interaksi jual-beli. Sarana yang digunakan dalam melakukan transaksi adalah bahasa. Dengan digunakannya bahasa, penjual dan pembeli dapat melakukan transaksi jual beli. Peristiwa tutur dalam wacana pedagang dan pembeli di pasar mempunyai peranan yang sangat penting, yaitu menyampaikan maksud dan tujuan dari dua belah pihak. Penjual dan pembeli sama-sama menggunakan bahasa sebagai sarana untuk menyampaikan maksud agar tercapainya kesepakatan. Interaksi antara penjual dan pembeli di pasar Tradisional Kedondong menggunakan bahasa Indonesia sebagai alat komunikasi disebut dengan peristiwa tutur.

Pasar tradisional Kedondong dijadikan lokasi penelitian, karena pasar Kedondong adalah pasar yang sering dikunjungi oleh masyarakat yang tinggal di Desa yang umumnya masih menggunakan ragam kedaerahaan dalam berbahasa. Letak Wilayah pasar Kedondong cukup strategis, karena letaknya di tengah masyarakat yang beragam suku, bahasa, dan agamanya sehingga tidak jarang terjadi ragam bahasa alih kode dan campur kode.

\section{METODE PENELITIAN}

Penelitian ini dilakukan bertujuan untuk mendeskripsikan bentuk dan faktor penyebab terjadinya alih kode dan campur kode di Pasar Tradisional Kedondong dan implikasinya pada pembelajaran bahasa Indonesia di SMA. Metode yang digunakan dalam penelitian ini adalah metode deskriptif kualitatif.

(Moleong, 2005: 5) Metode kualitatif antara lain bersifat deskriptif, data yang dikumpulkan lebih banyak berupa katakata atau gambar daripada angka-angka. Lebih jelas lagi, Kirk dan Miller (dalam Moleong, 2011: 4) mendefinisikan penelitian kualitatif adalah tradisi tertentu dalam ilmu pengetahuan sosial yang secara fundamental bergantung dari pengamatan pada manusia baik dalam kawasannya maupun dalam peristilahannya.

Sumber data pada penelitian ini adalah pedagang yang berjualan berbagai jenis macam barang, sayur-mayur, juga buahbuahan, dan pembeli yang sedang bertransaksi jual beli dengan pedagang tersebut.

peneliti di sini berperan sebagai instrumen penelitian Karena peneliti sendiri yang mencatat dan mengolah data yang berkaitan dengan penelitian ini, selain itu juga rekaman menjadi instrumen penelitian karena digunakan sebagai penguat data. Teknik pengumpulan data yang digunakan dalam penelitian ini adalah teknik obeservasi. Peneliti mengamati keadaan sekitar pasar Kedondong, mengamati jenis kelamin pedagang dan pembeli, raut wajah juga mimik pembeli dan penjual saat menawarkan, juga tuturan yang dituturkan oleh penjual dan pembeli. Pada saat observasi, peneliti juga menggunakan teknik simak bebas libat cakap simak bebas libat cakap. Teknik simak bebas merupakan teknik yang di dalamnya peneliti hanya bertindak sebagai peneliti, dan tidak terlibat dalam percakapan (Mahsun, 2005: 91-92).

Kemudian, Peneliti menggunakan teknik catat lapangan. Catatan lapangan yang digunakan yaitu catatan deskriptif dan reflektif. Catatan deskriptif merupakan uraian mengenai apa yang disimak, dilihat, dan dipikirkanselama proses pengumpulan data, sedangkan catatan reflektif merupakan interpretasi terhadap tuturan.

Untuk mempermudah peneliti memahami bahasa lisan yang dituturkan, peneliti menggunakan teknik rekam, yaitu merekam semua tuturan pedagang dan pembeli saat proses transaksi. 
Dalam hal ini analisis yang dilakukan runtutanya adalah sebagai berikut.

1. Mendengarkan rekaman sebagai langkah untuk memperkuat analisis

2. Mencatat tuturan percakapan yang mengandung alih kode dan campurkode ke dalam tabel data yang telah disiapkan.

3. Mengidentifikasi alih kode dan campur kode ke dalam indikator yangtelah disiapkan.

4. Menganalisis dan mengklasifikasikan bentuk-bentuk alih kode dancampur kode.

5. Menjelaskan bentuk-bentuk alih kode dan campur kode serta faktorfaktorpenyebabnya.

6. Mendeskripsikan faktor-faktor penyebab terjadinya alih kode dan campur kode.

7. Triangulasi data penelitian (mengecek kembali data yang telah diperoleh)

8. Mendeskripsikan implikasi alih kode dan campur kode pada percakapan antara pedagang dan pembeli di pasar Kedondong

\section{PEMBAHASAN}

Hasil penelitian yang dilakukan di pasar Tradisional Kedondong meliputi alih kode internal, alih kode eksternal tidak ditemukan dalam dalam penelitian ini . Campur kode yang ditemukan campur kode kata, frasa, dan klausa, namun data yang mendominasi adalah campur kode kata.

\section{A. Alih Kode Internal dan Faktor Penyebabnya}

Hasil penelitian menunjukkan bahwa ditemukan bentuk alih kode intern sedangkan alih kode ekstern tidak ditemukan dalam penelitian ini. Berikut ini data dan analisisnya.

\section{a. Alih Kode Internal yang Disebabkan oleh Pembicara}

Penjual : Apa bu?
Pembeli : Cabe ini (menunjuk cabai).

Penjual : Nyepok sai gokh khepa wih?

Pembeli : Sai kejung hinji.

Penjual : Pikha.

Pembeli : Lima ribu gawoh weh.

Penjual : Tomatne mawat?

Pembeli : Pikha tomatne?

Percakapan tersebut mengandung alih kode internal yang disebabkan oleh pembicara atau penutur. Penutur melakukan alih kode semata-mata untuk mengambil keuntungan dari peralihan kode yang dilakukanya. Penutur paham bahwa mitra tutur bersuku Lampung dilihat dari logat yang digunakanya sehingga penutur beralih kode dengan harapan pembeli nyaman ketika bertransaksi sehingga berpengaruh terhadap belanja lawan tutur.

\section{b. Alih Kode Internal yang Disebabkan Oleh Pendengar}

Penjual : Lepang nek (menawarkan timun)?

Pembeli : Iyu lepang, setengah kilo bae!

Penjual : Setengah kilo bae? Tangkilna henteu?

Pembeli : Henteu dahar deui.

Penjual : Nuhun nek (sambil memberikan barang belanjaan).

Pada percakapan tersebut mengandung alih kode internal dari bahasa Lampung ke bahasa Sunda yang disebabkan oleh pendengar atau lawan tutur. Penutur mengimbangi peralihan bahasa dari bahasa Lampung ke bahasa Sunda yang dilakukan mitra tutur karena penutur memahami bahwa kosakata bahasa Lampung yang dikuasai pendengar cukup minim dan lebih nyaman menggunakan bahasa pertamanya yaitu bahasa Sunda.

\section{B. Campur Kode dan Faktor Penyebabnya}

a. Campur Kode Kata

Berikut ini pemaparan campur kode yang kata dan faktor penyebabnya. 


\section{a) Campur Kode Kata yang Disebabkan oleh Latar Belakang Sikap Penutur}

Penjual : Apa mak?

Pembeli : Ini cabe kecil-kecil ya?

Penjual : Kecil-kecil tapi lalak (pedas) mak.

Pembeli : Enggak lah.

Percakapan tersebut mengandung campur kode kata yang disebabkan oleh latar belakang sikap penutur. Sisipan berupa kata dalam bahasa Lampung lalak yang berarti "pedas" yang menyebabkan percakapan tersebut termasuk ke dalam percakapan campur kode kata. Penutur dan mitra tutur memiliki latar sosial yang sama sehingga penutur melakukan campur kode agar pembicaraan lebih akrab.

\section{b) Campur Kode Kata yang Disebabkan oleh Kebahasaan}

Penjual : Beli berapa?

Pembeli : Iyeu berapa?(sambil menunjuk timun) Sekilo bae berapa?

Penjual : Dua ribu aja.

Pembeli : iya dua ribu bae.

Percakapan tersebut mengandung campur kode kata yang disebabkan oleh faktor kebahasaan. Sisipan berupa kata bahasa Sunda iye yang berarti "ini" dan bae yang

berarti "saja" yang menyebabkan percakapan tersebut termasuk ke dalam campur kode kata. Mitra tutur menggunakan kata iyeu dan bae dalam bahasa Sunda karena lebih menguasai dibanding padanan katanya dalam bahasa Indonesia.

\section{c) Campur Kode Kata yang} Disebabakan oleh Keterbatasan Kode Pembeli : Berapa yang ini ? (kerupuk)

Pejual : Dua ribu.

Pembeli : Yaudah ambil empat aja

Penjual : Kagol bu sekalian lima aja ?

Pembeli : Yaudah lima sekalian

Penjual : Oke teh.
Percakapan tersebut mengandung campur kode kata yang disebabkan oleh keterbatasan kode. Sisipan berupa kata bahasa Sunda kagol yang berarti "tanggung" dan teh yang berarti "mba" yang menyebabkan percakapan tersebut termasuk ke dalam percakapan campur kode kata. Penutur menggunakan kata kagol dan teh dalam bahasa Sunda karena tidak mengerti padanan kata dalam bahasa Indonesia.

\section{b. Campur Kode Frasa}

Berikut akan dipaparkan campur kode frasa dan faktor penyebabnya.

a) Campur Kode Frasa yang Disebabkan oleh Faktor Kebahasaan Pembeli : Berapaan sih kerupuknya?

Penjual : Empat ribu bu.

Pembeli : Sepuluh ribu telu yo?

Penjual : Gak boleh pak.

Pembeli : Yaudah kalo gak boleh.

Percakapan tersebut mengandung campur kode frasa faktor kebahasaan. Sisipan berupa frasa bahasa Jawa telu yo yang berarti "tiga ya" yang menyebabkan percakapan tersebut termasuk ke dalam campur kode frasa. Mitra tutur menggunakan kata telu yo dalam bahasa Jawa karena lebih menguasai dibanding padanan katanya dalam bahasa Indonesia.

\section{b) Campur Kode Frasa yang} Disebabkan oleh Faktor Pembicara

Penjual : Beli apa?

Pembeli : Bawang.

Penjual : Beraha?

Pembeli : Tiga ribu

Penjual : Terus naon dei?

Pembeli : Udah itu aja.

Percakapan tersebut mengandung campur kode frasa karena faktor pembicara.

Sisipan berupa frasa bahasa Sunda naon dei yang berarti "apa lagi” yang 
menyebabkan percakapan ini termasuk ke dalam campur kode klausa.

Penutur melakukan campur kode karena memiliki maksud tertentu. Penutur bermaksud membuat mitra tutur merasa nyaman berkomunikasi karena penutur bercampur kode menggunakan bahasa pertama mitra tutur sehingga berimbas pada belanja mitra tutur yang lebih banyak.

\section{c. Campur Kode Klausa}

Berikut akan dipaparkan campur kode klausa yang disebabkan oleh faktor kebahasaan.

Penjual : Timun bu?

Pembeli : Iya 2 ribu aja.

Penjual : Dua ribu ya? Gak nambah?

Penjual : Henteu, iye bae.

Percakapan tersebut mengandung campur kode klausa yang disebabkan oleh faktor kebahasaan. Sisipan berupa klausa dalam bahasa Sunda henteu, iyeu bae yang berarti " tidak, ini saja" yang menyebabkan percakapan tersebut termasuk dalam campur kode klausa.

Mitra tutur menggunakan klausa henteu, iye bae karena lebih menguasai dibanding padanan kata dalam bahasa Indonesia.

\section{Implikasi Alih Kode dan Campur Kode pada Pembelajaran Bahasa di SMA}

Hasil penelitian alih kode dan campur kode di Pasar Tradisional Kedondong berimplikasi terhadap pembelajaran bahasa Indonesia di SMA. Di dalamanya terdapat materi-materi dan keterampilan dalam pembelajaran bahasa Indonesia. Alih kode ini merupakan salah satu keterampilan berbahasa, yang termasuk dalam keterampilan berbicara. Keterampilan berbicara merupakan salah satu dari keterampilan yang diajarkan dalam mata pelajaran bahasa Indonesia. Dalam Kurikulum 2013, yang berbasis teks keterampilan berbahasa tidak sepenuhnya secara langsung diajarkan. keterampilan berbahasa tetap diajarkan kepada siswa namun, melalui materi yang berupa teks.

Salah satu materi yang sekaligus mengajarkan keterampilan berbicara adalah teks negosiasi. Teks negosiasi merupakan teks yang mengajarkan materi keterampilan berbahasa dalam hal perniagaan, jual beli atau tawar menawar.

Materi tersebut terdapat dalam silabus kelas X SMA semester genap pada KD sebagai berikut.

3.11 Menganalisis isi, struktur (orientasi, pengajuan, penawaran, persetujuan, penutup) dan kebahasaan teks negosiasi.

4.11 Mengonstruksikan teks negosiasi dengan memerhatikan isi, struktur (orientasi, pengajuan, penawaran, persetujuan, penutup) dan kebahasaan.

\section{SIMPULAN DAN SARAN}

\section{A. Simpulan}

1) Bentuk Alih Kode

Bentuk alih kode yang ditemukan dalam penelitian ini adalah alih kode internal karena dalam pergantianya masih dalam lingkup nasional atau antardialek.

2) Faktor Penyebab Alih Kode Faktor yang disebabkan oleh pembicara atau penutur, dan pendengar atau lawan tutur.

3) Bentuk Campur kode

Bentuk campur kode yang ditemukan dalam penelitian ini ada beberapa bentuk yaitu campur kode yang penyisipanya berupa kata, frasa, dan klausa.

4) Faktor Penyebab Campur Kode Campur kode yang disebabkan oleh latar belakang sikap penutur, kebahasaan, keterbatasan kode, dan pembicara. 
Kaitannya secara langsung terhadap pembelajaran, yaitu antara alih kode dan campur kode di pasar tradisional Kedondong dengan pembelajaran teks negosiasi di SMA sebagai contoh percakapan teks negosiasi yang disajikan kepada siswa melalui RPP agar lebih terkonsep dalam proses pembelajaran. Selain itu, contoh percakapan tersebut akan mendorong siswa untuk mampu meningkatkan kemampuan berbicara dan berbahasa secara baik

\section{B. Saran}

1.Pembaca dapat mengambil informasi mengenai peristiwa alih kode dan campur kode dalam berkomunikasi. Peneliti lain yang tertarik pada bidang yang sama perlu mengadakan penelitian mengenai alih kode dan campur kode yang dilakukan di lingkungan selain pasar tradisional yang menjadi subjek penelitian. Selain itu, penelitian alih kode dan campur kode telah banyak yang meneliti, seyogyanya peneliti yang akan meneliti di masa mendatang lebih memperdalam dan menambah apa yang belum diulas dari penelitian yang telah ada.

2. Pendidik sekaligus pengajar. Dengan adanya penelitian semacam ini hendaknya selain mengasah kemampuan berbahasa atau berbicara siswa, juga dapat dapat menghargai keragaman suku bangsa dan bahasa sebagai sarana pembelajaran yang baik.

\section{DAFTAR PUSTAKA}

Chaer, Abdul dan Agustina. 2010. Sosiolinguistik Perkenalan Awal. Jakarta:Rineka Cipta.

Kridalaksana. 2008. Kamus Linguistik. Jakarta: Gramedia Pustaka Utama.

Mahsun. 2005. Metode Penelitian Bahasa: Tahapan, Strategi, dan Tekniknya. Jakarta: PT Raja Grafindo Persada.

Moleong, Lexy. J. 2005. Metodologi Penelitian Kualitatif.

Bandung:Remaja Rosdakarya.

Nababan, P.W.J. 1984. Sosiolinguistik : Suatu Pengantar. Jakarta: PT. Gramedia.

Pateda, Mansoer. 1987. Sosiolinguistik. Bandung: Angkasa.

Suandi. 2014. Sosiolinguistik. Yogyakarta: Graha Ilmu.

Suwito. 1983. Pengantar Awal Sosiolinguistik (Teori dan Problema). Surakarta: Henary Offset Solo.

Suyanto, Edi. 2011. Membina, Memelihara, dan Menggunakan Bahasa Indonesia Secara Benar (Bahan Ajar). Yogyakarta: Ardana Media. 